\title{
An evaluation on phase behaviors of gas condensate reservoir in cyclic gas injection
}

\author{
Angang Zhang*, Zifei Fan, Lun Zhao, and Anzhu Xu \\ Research Institute of Petroleum Exploration and Development, PetroChina, 20 Xueyuan Road, Haidian, Beijing 100083, PR China
}

Received: 22 October 2019 / Accepted: 18 December 2019

\begin{abstract}
Maintaining the reservoir pressure by gas injection is frequently adopted in the development of gas condensate reservoir. The aim of this work is to investigate the phase behavior of condensate oil and remaining condensate gas in the formation under gas injection. The DZT gas condensate reservoir in East China is taken as an example. The multiple contact calculation based on cell-to-cell method and phase equilibrium calculations based on PR Equation of State (EOS) were utilized to evaluate the displacement mechanism and phase behavior change. The research results show that different pure gas has different miscible mechanism in the displacement of condensate oil: vaporizing gas drive for $\mathrm{N}_{2}$ and $\mathrm{CH}_{4}$; condensing gas drive for $\mathrm{CO}_{2}$ and $\mathrm{C}_{2} \mathrm{H}_{6}$. Meanwhile, there is a vaporing gas drive rather than a condensing gas drive for injecting produced gas. When the condensate oil is mixed with 0.44 mole fraction of produced gas, the phase behavior of the petroleum mixture reverses, and the condensate oil is converted to condensate gas. About the reinjection of produced gas, the enrichment ability of hydrocarbons is better than that of no-hydrocarbons. After injecting produced gas, retrograde condensation is more difficult to occur, and the remaining condensate gas develops toward dry gas.
\end{abstract}

\section{Introduction}

During the development of gas condensate reservoir, the retrograde condensation happened when the reservoir pressure drops below the dew point pressure. Generally, the condensate oil cannot flow in the porous media until its saturation is greater than a threshold value that is called the critical flowing saturation. Hence, a larger amount of condensate oil is trapped in the formation and is hard to the produced to the surface. Worse, the condensate oil blocks the flow path of gas and decreases the productivity of gas well (Fetkovich, 1973; Fevang and Whiston, 1996; Muskat, 1950). In order to prevent the participation of condensate oil, maintaining the reservoir pressure is significant for the efficient development of gas condensate reservoir.

At present, there are two ways to maintain the reservoir pressure: water injection and gas injection. Although many scholars have conducted a lot of research on the water injection of gas condensate reservoir (Cason, 1989; Fishlock and Probert, 1996; Henderson et al., 1993; Matthews et al., 1988), there are still disadvantages such as the gas trapping and water breakthrough. Thus, gas injection is still the preferred option for the development of gas condensate reservoir (Ayala and Ertekin, 2005; Chen et al., 2012; Diamond and Rondon, 1990; Jessen and Orr, 2003; Li et al., 2016). Standing et al. (1948) pointed out that all

\footnotetext{
* Corresponding author: zhangangang@petrochina.com.cn
}

the condensate oil can be produced if there are enough gas to be injected into the reservoir. Abel et al. (1970) concluded that increasing the gas-injection pressure is beneficial to enhance the recovery of condensate oil by performing laboratory experiment on the actual reservoir. Shtepani (2006) found that $\mathrm{CO}_{2}$ injection can generate a vaporizing gas drive for the condensate oil trapped in the formation, and improve the recovery efficiency of condensate oil. Li et al. (2001) summarized that dry gas injection can evaporate both the intermediate and heavy components of the condensate in the formation. Taheri et al. (2013) studied the mechanism of enhancing condensate recovery by gas injection, and found that the vaporizing gas drive is the main reason by comparing three injected gas of $\mathrm{CH}_{4}, \mathrm{~N}_{2}$ and $\mathrm{CO}_{2}$. Li et al. (2004) pointed out the alternate injection of dry gas and $\mathrm{N}_{2}$ is better to enhance the condensate recovery than natural depletion or pure $\mathrm{N}_{2}$ injection. Guo et al. (2004) carried out the depletion experiment of actual condensate gas in both the PVT tube and long core, and concluded that the condensate recovery in the long core is greater than that in the PVT tube. Jiao et al. (2012) found that the phase envelope of condensate gas shrinks and develops to the shape of dry gas during the Constant Volume Depletion (CVD). Zhu (2015) took Yaha gas condensate reservoir as an example to investigate the phase behavior of condensate gas, and drawn the conclusion that the recovery percent of condensate oil increases by $13.55 \%$ after injecting $0.85 \mathrm{PV}$ of dry gas. 
Table 1. The pseudo-composition of condensate gas and the critical parameters of EOS.

\begin{tabular}{lccccccc}
\hline Components & $\begin{array}{c}\text { Mole fraction } \\
(\%)\end{array}$ & $\begin{array}{c}\text { Mole weight } \\
(\mathrm{g} / \mathrm{mol})\end{array}$ & $\begin{array}{c}\text { Critical pressure } \\
(\mathrm{bar})\end{array}$ & $\begin{array}{c}\text { Critical temperature } \\
(\mathrm{K})\end{array}$ & $\begin{array}{l}\text { Omega } \\
\text { Omega }\end{array}$ & $\begin{array}{c}\text { Acentric } \\
\text { factor }\end{array}$ \\
\hline $\mathrm{CO}_{2}$ & 1.22 & 44.0 & 73.9 & 304.7 & 0.4572 & 0.0778 & 0.225 \\
$\mathrm{~N}_{2}$ & 2.13 & 28.0 & 33.9 & 126.2 & 0.4572 & 0.0778 & 0.040 \\
$\mathrm{C}_{1}$ & 65.80 & 16.0 & 46.0 & 190.6 & 0.4572 & 0.0778 & 0.013 \\
$\mathrm{C}_{2}$ & 8.51 & 30.1 & 48.8 & 305.4 & 0.4572 & 0.0778 & 0.099 \\
$\mathrm{C}_{3}$ & 5.86 & 44.1 & 42.5 & 369.8 & 0.4572 & 0.0778 & 0.152 \\
$\mathrm{C}_{4-6}$ & 9.89 & 66.9 & 36.6 & 447.7 & 0.4572 & 0.0778 & 0.200 \\
$\mathrm{C}_{7+1}$ & 4.89 & 107.8 & 29.7 & 567.1 & 0.4572 & 0.0778 & 0.345 \\
$\mathrm{C}_{7+2}$ & 1.45 & 198.5 & 18.2 & 713.6 & 0.4572 & 0.0778 & 0.645 \\
$\mathrm{C}_{7+3}$ & 0.25 & 335.1 & 10.2 & 851.2 & 0.4572 & 0.0778 & 1.067 \\
\hline
\end{tabular}

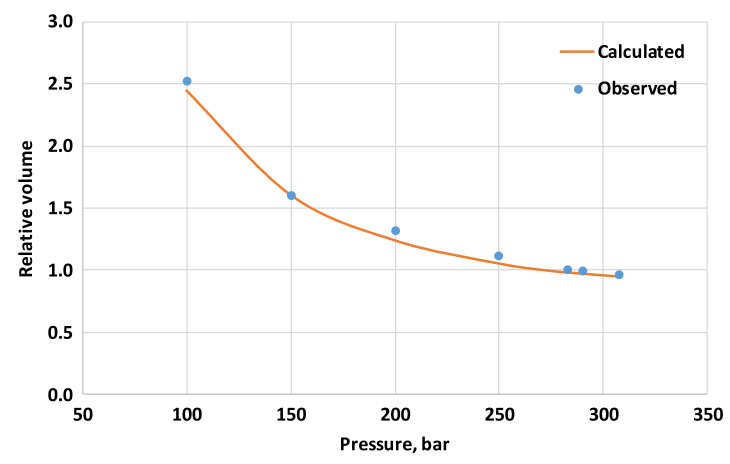

(a) Relative volume versus pressure from $\mathrm{CCE}$

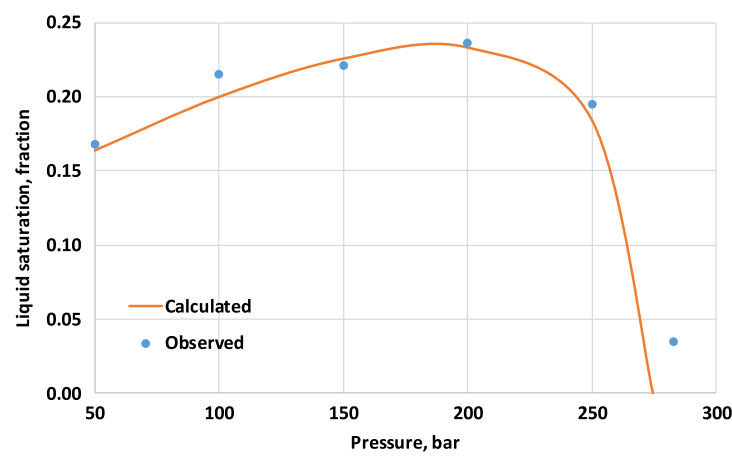

(b) Liquid saturation versus pressure from CVD

Fig. 1. The fitting results of PVT experimental data.

The main focus of this paper is to evaluate the phase behavior of condensate oil and remaining condensate gas in the formation with gas injection. In this paper, the multiple contact between different pure gas and condensate oil in the formation were firstly performed based on the cellto-cell method. Then, the phase behavior of condensate oil mixed with different mole fraction of produced gas was evaluated. Minimum Miscible Pressure (MMP) and Minimum Miscible Enrichment (MME) for injecting produced gas were obtained by multiple-contact calculations. Finally, the phase behavior of remaining condensate gas mixed with different mole fraction of produced gas was analyzed in detail.

\section{Model description}

The condensate gas of the DZT reservoir in East China was divided into nine pseudo-components according to its characterization. The composition of original condensate gas is given in Table 1 . The mole fraction of $\mathrm{C}_{1}$ is $65.8 \%$, the mole fraction of $\mathrm{C}_{2}-\mathrm{C}_{6}$ adds up to $24.26 \%$, and the mole fraction of $\mathrm{C}_{7+}$ is $6.59 \%$. The dew point pressure is about $280 \mathrm{bar}$ at the reservoir temperature of $366.5 \mathrm{~K}$.

Based on the software of PVTi simulator, the critical parameters of Equation of State (EOS) for each component were obtained through fitting the experimental results

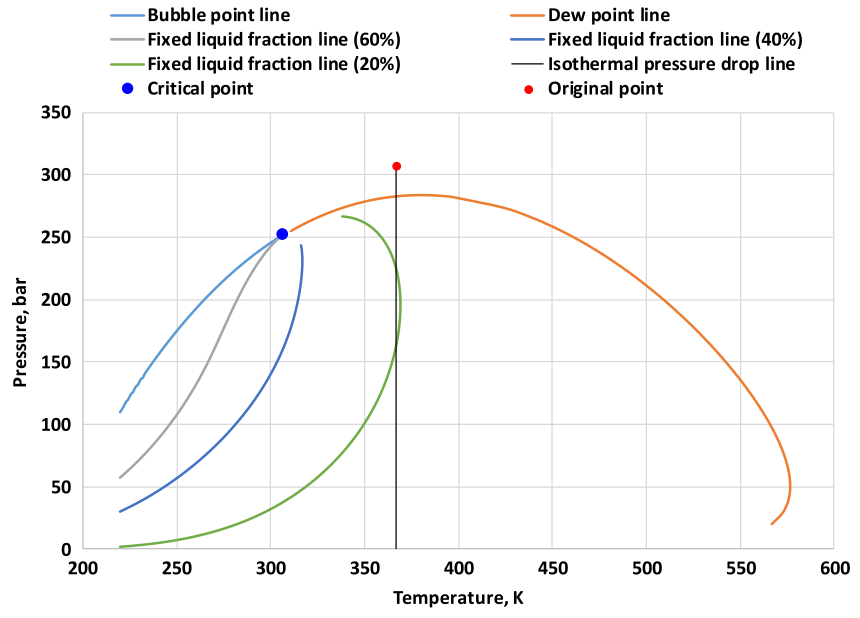

Fig. 2. Phase plot of the gas condensate reservoir under original condition.

which include the experiments of Constant Composition Expansion (CCE) and Constant Volume Depletion (CVD). Figure 1 shows that the fitting results coincide with the experiment data very well. The critical parameters of EOS are also presented in Table 1 . The phase plot of this gas condensate reservoir is shown in Figure 2. And the crit- 
Table 2. Properties of the one-layer gas model.

\begin{tabular}{lc}
\hline Parameter & Value \\
\hline Grid size & $100 \times 100 \times 1$ \\
Grid increment & $5 \mathrm{~m} \times 5 \mathrm{~m} \times 5 \mathrm{~m}$ \\
Porosity & $15 \%$ \\
Permeability & $40 \mathrm{mD}$ \\
Connate water saturation & 0.15 \\
critical flow saturation of & 0.1 \\
$\quad$ condensate oil & $366.5 \mathrm{~K}$ \\
Reservoir temperature & $308 \mathrm{bar}$ \\
\hline
\end{tabular}

ical pressure and critical temperature is 252.0 bar and $306.7 \mathrm{~K}$, respectively.

In order to gain the composition of each component in the reservoir fluid during the natural depletion, we resort to numerical simulation of one-layer model on the basis of E300 compositional simulator. The properties of this onelayer gas condensate model are given in Table 2 . The producer is located in the corner of the model respectively, and was produced by the fixed gas rate of $10 \times 10^{3} \mathrm{~m}^{3} / \mathrm{d}$.

When the reservoir pressure was depleted to 219.3 bar, the composition of remaining condensate gas and condensate oil in the reservoir is shown in Table 3. Under this reservoir pressure, the condensate oil consists of $50.1 \%$ light component $\left(\mathrm{C}_{1}+\mathrm{N}_{2}\right), 30.85 \%$ intermediate component $\left(\mathrm{C}_{2-6}+\mathrm{CO}_{2}\right)$ and $18.05 \%$ heavy component $\left(\mathrm{C}_{7+}\right)$. And the remaining condensate gas contains $72.66 \%$ light component, $23.79 \%$ intermediate component and $3.55 \%$ heavy component. The phase plot of condensate oil and remaining condensate gas is shown in Figure 3. It can be easily seen from Figure 3, the condensate oil belongs to the type of volatile oil. Compared to the original condensate gas, the two-phase zone of the remaining condensate gas shrinks, and both the critical pressure and critical temperature decrease. This indicates that the remaining condensate gas develops toward the dry gas, and the condensate content is getting lower and lower.

\section{Phase behavior evaluation of reservoir fluid under gas injection}

\subsection{Condensate oil}

\subsubsection{Pure gas injection}

In order to evaluate the influence of injected gas type on the phase behavior of condensate oil in the formation, the multiple contact between different pure gas and condensate oil were performed using the cell-to-cell calculation method presented by Metcalfe et al. (1973), Pederson et al. (1986) and Jaubert et al. (1998). This method simulates a mass of cells of equal volume in a series, of which the temperature and pressure keep the same. Ternary plot is usually used to determine whether or not the miscibility has been achieved. Three groups of components including light component $\left(\mathrm{C}_{1}+\mathrm{N}_{2}\right)$, intermediate component $\left(\mathrm{C}_{2-6}+\mathrm{CO}_{2}\right)$ and heavy component $\left(\mathrm{C}_{7+}\right)$, were used to demonstrate the phase behavior in ternary plot. Figure 4 shows the ternary plots for pure $\mathrm{CH}_{4}, \mathrm{~N}_{2}, \mathrm{CO}_{2}$ and $\mathrm{C}_{2} \mathrm{H}_{6}$ injection when Multiple Contact Miscibility (MCM) was achieved. From Figure 4, it can be easily found that the phase envelopes of different pure gas are quite different. The bell-shaped phase envelopes were generated for pure $\mathrm{CH}_{4}$ and $\mathrm{N}_{2}$, and hourglass-shaped phase envelopes for pure $\mathrm{CO}_{2}$ and $\mathrm{C}_{2} \mathrm{H}_{6}$.

Figure 5 shows the minimum pressure of MCM and FCM (First Contact Miscibility) with different gas type. From Figure 5, the miscibility ability increases in the following order: $\mathrm{N}_{2}, \mathrm{CH}_{4}, \mathrm{CO}_{2}$ and $\mathrm{C}_{2} \mathrm{H}_{6} . \mathrm{N}_{2}$ injection has the maximum value of 274 bar for MCM and 1162 bar for FCM; $\mathrm{C}_{2} \mathrm{H}_{6}$ injection has the minimum value of 116 bar for MCM and 230 bar for FCM. It indicates that the greater the content of $\mathrm{CO}_{2}$ and $\mathrm{C}_{2} \mathrm{H}_{6}$, the easier the miscibility.

The pressure-composition diagram for different gas type is presented in Figure 6. It can be seen that the saturation pressure of $\mathrm{N}_{2}$ keeps increasing rapidly, while that of $\mathrm{CH}_{4}$ increases first then decreases and that of $\mathrm{CO}_{2}$ and $\mathrm{C}_{2} \mathrm{H}_{6}$ keeps decreasing. The pressure-composition diagram also indicates that a vaporizing gas drive for $\mathrm{N}_{2}$ and $\mathrm{CH}_{4}$ since the critical point is to the left of the cricondenbar, and a condensing gas drive for $\mathrm{CO}_{2}$ and $\mathrm{C}_{2} \mathrm{H}_{6}$ as the critical point is to the right of the cricondenbar. It should be noted that the displacement of crude oil by enriched gas exhibits the mechanism of both condensing gas drive and vaporizing gas drive (Zick, 1986). He addressed that the combined condensing/vaporizing mechanism can generate displacements that are effectively miscible, but true miscibility may not actually occur.

\subsubsection{Produced gas injection}

Based on the phase equilibrium model (Chueh and Prausnitz, 1967; Obut et al., 1986; Yang and Wei, 2004) and PR EOS (Peng and Robinson, 1976), the phase behavior of condensate oil mixed with different mole fraction of produced gas were performed as shown in Figure 7. Here, the injection-gas refers to the produced gas. The mole fraction of injection gas $(f)$ is defined as the mole ratio of injection gas to condensate oil. And the composition of produced gas is given by Table 3 . Figure 7 shows that when the mole fraction of injection gas is greater, the critical point of condensate oil moves closer to the original reservoir conditions (the original pressure and temperature are 308 bar and $366.5 \mathrm{~K}$ respectively). For example, the critical pressure and temperature of condensate oil is 234.9 bar and $497 \mathrm{~K}$, and they move to 303.1 bar and $388.8 \mathrm{~K}$ when the mole fraction of injection gas is 0.4 . It means that the greater the mole fraction of injection gas, the more volatile the condensate oil. It can also be easily found that when the mole fraction of injection gas is up to 0.5 , the shape of phase plot begins to change and the critical temperature is less than the reservoir temperature. It indicates that the reversal of phase behavior occurs; that is, the condensate oil is converted to condensate gas.

Figure 8 shows the relationship between the volume of condensate oil and reservoir pressure when the condensate oil was mixed with different mole fraction of produced 
Table 3. Component mole fraction of reservoir fluid and produced gas at the reservoir pressure of 219.3 bar.

\begin{tabular}{lcccc}
\hline Component & \multicolumn{3}{c}{ Mole fraction of the reservoir fluid } & $\begin{array}{c}\text { Mole fraction of the produced } \\
\text { gas (re-injected gas) } \\
\text { (\%) }\end{array}$ \\
\cline { 2 - 3 } $\begin{array}{c}\text { In the liquid phase } \\
\text { (condensate oil) }(\%)\end{array}$ & $\begin{array}{c}\text { In the vapor phase (remaining } \\
\text { condensate gas) }(\%)\end{array}$ & $\begin{array}{c}\text { Total mole } \\
\text { fraction (\%) }\end{array}$ & 1.27 \\
\hline $\mathrm{CO}_{2}$ & 1.18 & 1.22 & 1.21 & 2.21 \\
$\mathrm{~N}_{2}$ & 1.21 & 2.13 & 1.92 & 73.52 \\
$\mathrm{C}_{1}$ & 48.89 & 70.53 & 65.5 & 8.93 \\
$\mathrm{C}_{2}$ & 8.71 & 8.69 & 8.69 & 5.53 \\
$\mathrm{C}_{3}$ & 7.04 & 5.61 & 5.94 & 7.17 \\
$\mathrm{C}_{4-6}$ & 14.92 & 8.27 & 9.82 & 1.37 \\
$\mathrm{C}_{7+1}$ & 10.97 & 3.09 & 4.92 & 0 \\
$\mathrm{C}_{7+2}$ & 5.57 & 0.44 & 1.64 & 0 \\
$\mathrm{C}_{7+3}$ & 1.51 & 0.02 & 0.37 & 0 \\
\hline
\end{tabular}

gas. It can be seen from Figure 8, the shrinkage of condensate oil becomes higher when the mole fraction of injection gas is greater. For instance, at the same pressure of 200 bar, the mole fraction of condensate oil in the mixture system declines from $80.43 \%$ to $25.15 \%$ when the mole fraction of injection gas increases from 0 to 0.6 . Furthermore, the curve shape in Figure 8 begins to change when the mole fraction of injection gas is 0.5 . The volume of condensate oil decreases with reservoir pressure when the mole fraction of injection gas is less than 0.5; however, when the mole fraction of injection gas is greater than 0.5 , it increases first and then decreases as the reservoir pressure declines. It also means that the phase behavior of the mixture system reverses, that is, the condensate oil is converted to condensate gas after injecting enough produced gas. Figure 9 shows the pressure-composition relation for injecting produced gas. The critical mole fraction of injection gas is defined as the one which make the reversal of phase behavior happen. In the pressure-composition diagram, the critical mole fraction of injection gas corresponds to the critical point. From Figure 9, it can be seen that the critical mole fraction of injection gas is 0.44 . Figure 9 also indicates a vaporing gas drive rather than a condensing gas drive for injecting produced gas.

The multiple contact between condensate oil and produced gas can be also simulated by cell-to-cell method. Figure 10 shows the ternary plot from multiple contact calculation for injecting produced gas. Figure 10a shows a vaporizing gas drive at the pressure of $250 \mathrm{bar}$; as the envelope for the vaporizing process is not closed, the miscibility was not achieved. As the reservoir pressure grows up to 274 bar, the envelope closes indicating the MCM occurs, as shown in Figure 10b. It means that increasing the gasinjection pressure can achieve the miscibility under the reservoir temperature of $366.5 \mathrm{~K}$.

Besides, the miscibility can also be achieved by increasing the content of intermediate component $\left(\mathrm{C}_{2-6}+\mathrm{CO}_{2}\right)$ in the produced gas at the current reservoir pressure (219.3 bar) and reservoir temperature $(366.5 \mathrm{~K})$. This process is usually called the injection-gas enrichment. Based on the predictive method presented by Jaubert et al. (1995), we obtained the MME of different enrichment agent

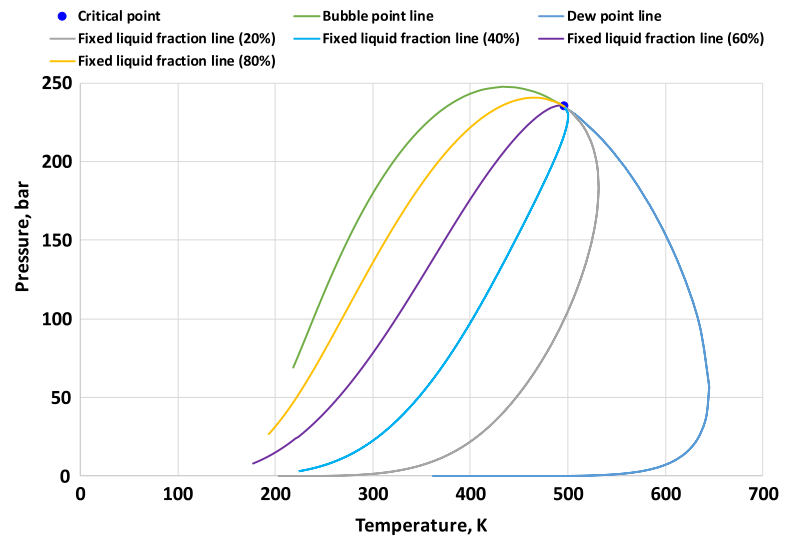

(a) Condensate oil

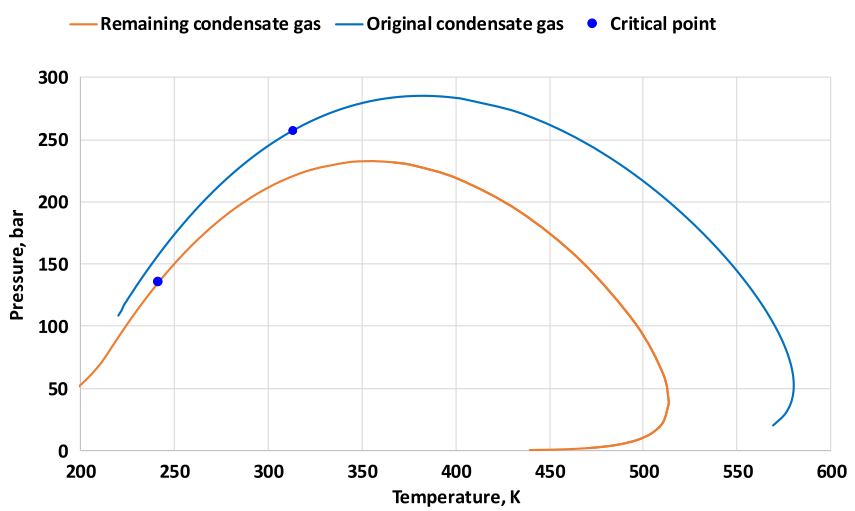

(b) Remaining condensate gas

Fig. 3. Phase plot of condensate oil and remaining condensate gas in the reservoir at the pressure of 219.3 bar.

$\left(\mathrm{CO}_{2}, \mathrm{C}_{2} \mathrm{H}_{6}, \mathrm{C}_{3} \mathrm{H}_{8}\right.$ and $\left.\mathrm{C}_{4-6}\right)$. The ternary plots for different enrichment agent when the miscibility was achieved are shown in Figure 11. As can be seen from Figure 11, the phase envelopes for different enrichment agent are different. The triangle-shaped curves are formed for the make-up gas (enrichment agent) of $\mathrm{CO}_{2}$ and $\mathrm{C}_{2} \mathrm{H}_{6}$, and 


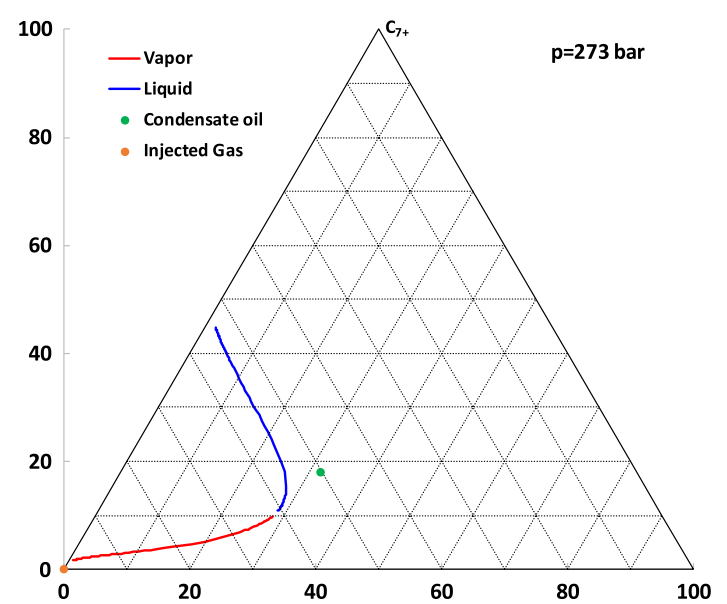

(a) $\mathrm{CH}_{4}$

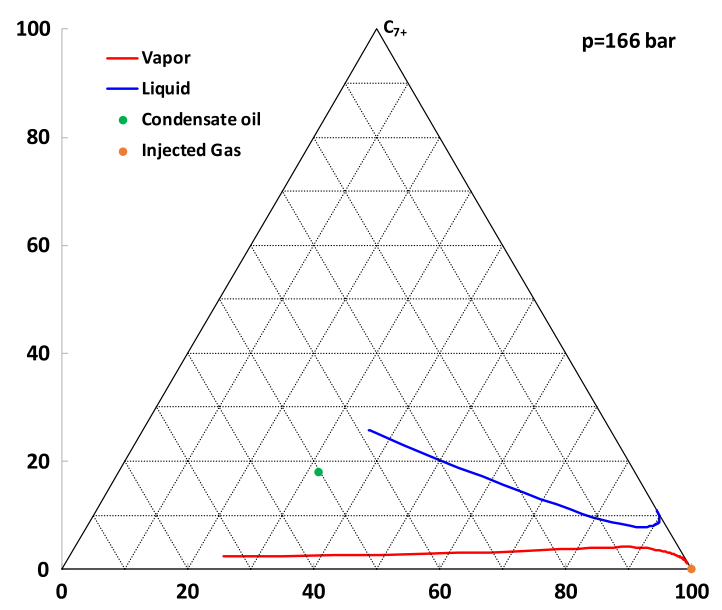

(c) $\mathrm{CO}_{2}$

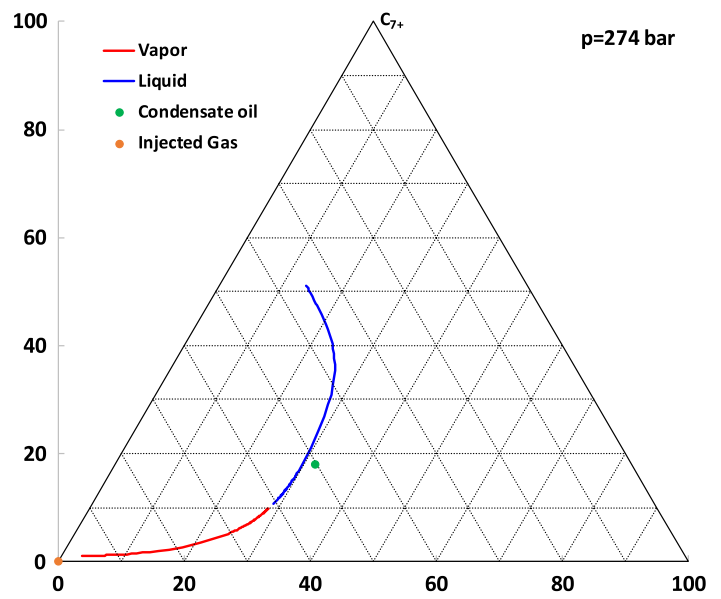

(b) $\mathrm{N}_{2}$

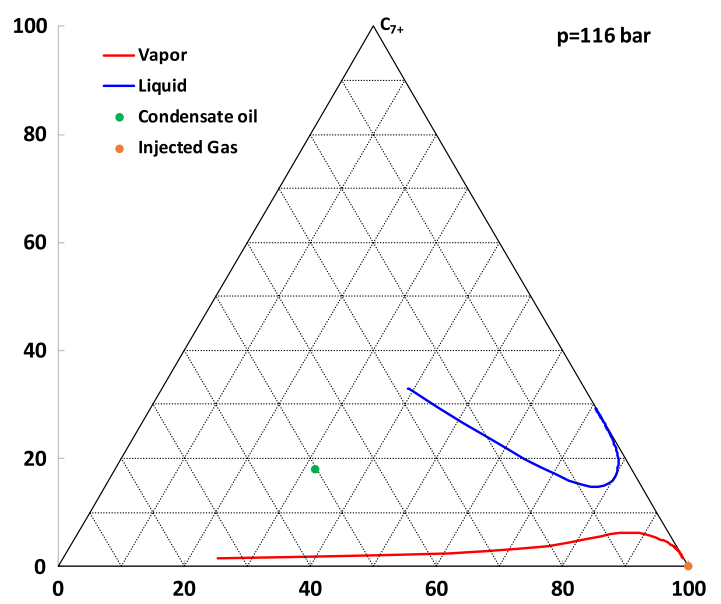

(d) $\mathrm{C}_{2} \mathrm{H}_{6}$

Fig. 4. Ternary plots for pure $\mathrm{CH}_{4}, \mathrm{~N}_{2}, \mathrm{CO}_{2}$ and $\mathrm{C}_{2} \mathrm{H}_{6}$ injection at $366.5 \mathrm{~K}$.

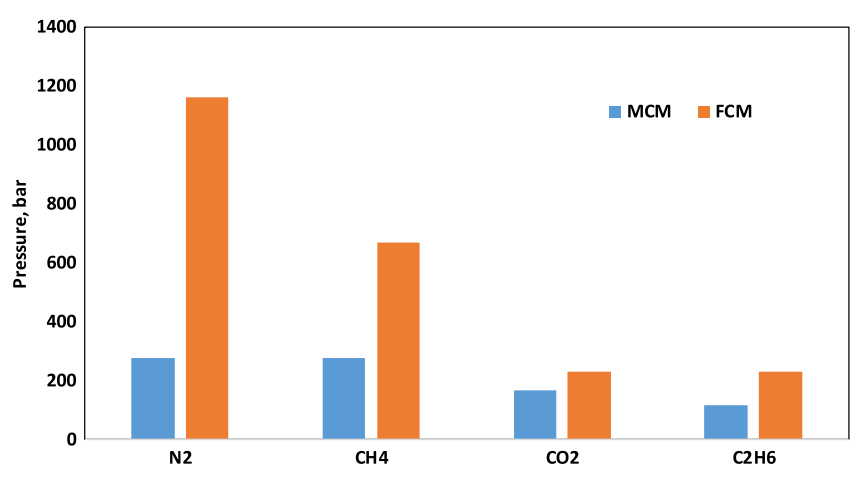

Fig. 5. Minimum pressure of MCM and FCM with different gas type.

half-hourglass-shaped curves for $\mathrm{C}_{3} \mathrm{H}_{8}$ and $\mathrm{C}_{4-6}$. The MME of different enrichment agent decreases as follows: $\mathrm{CO}_{2}$, $\mathrm{C}_{2} \mathrm{H}_{6}, \mathrm{C}_{3} \mathrm{H}_{8}$ and $\mathrm{C}_{4-6}$. The MME of $\mathrm{CO}_{2}$ has the maximum

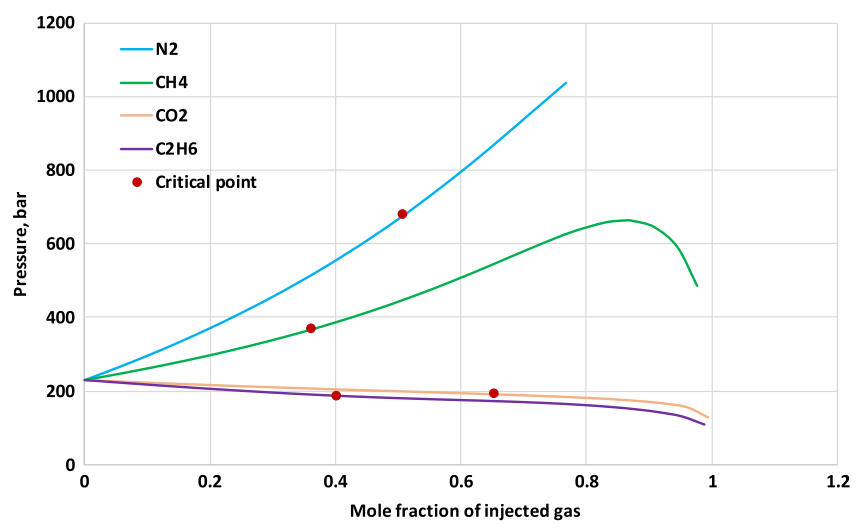

Fig. 6. Pressure-composition diagram for different gas type.

value of 0.71 , and that of $\mathrm{C}_{4-6}$ has the minimum value of 0.10 . It also indicates that the enrichment ability of hydrocarbons is better than that of no-hydrocarbons as expected. 


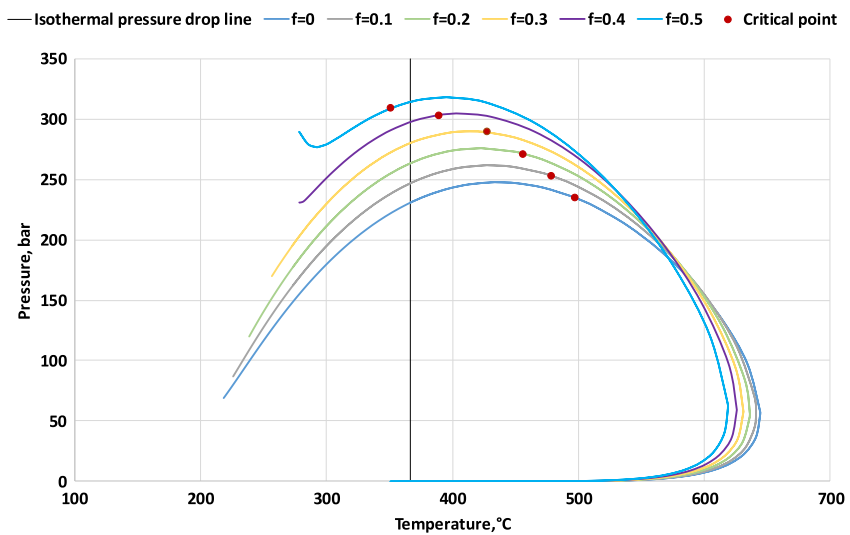

Fig. 7. Phase plot of condensate oil mixed with different mole fraction of produced gas.

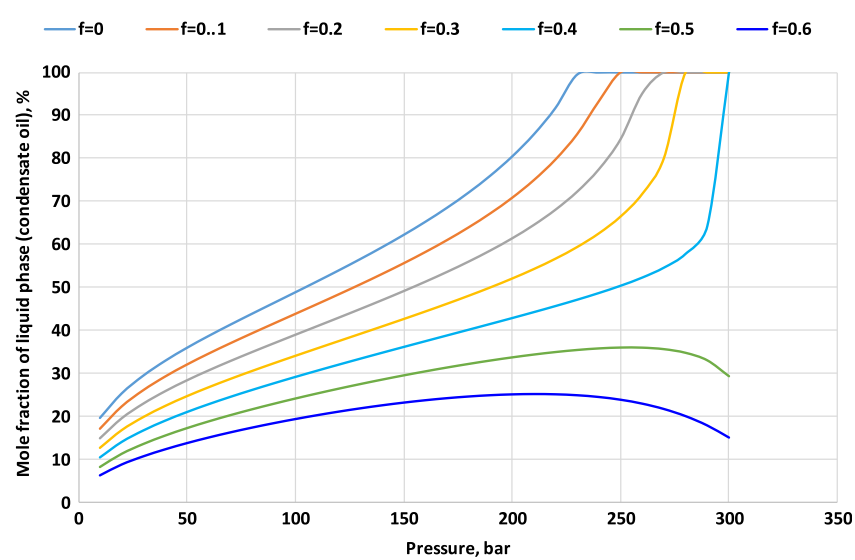

Fig. 8. The effect of mole fraction of injection gas (produced gas) on the condensate oil volume.

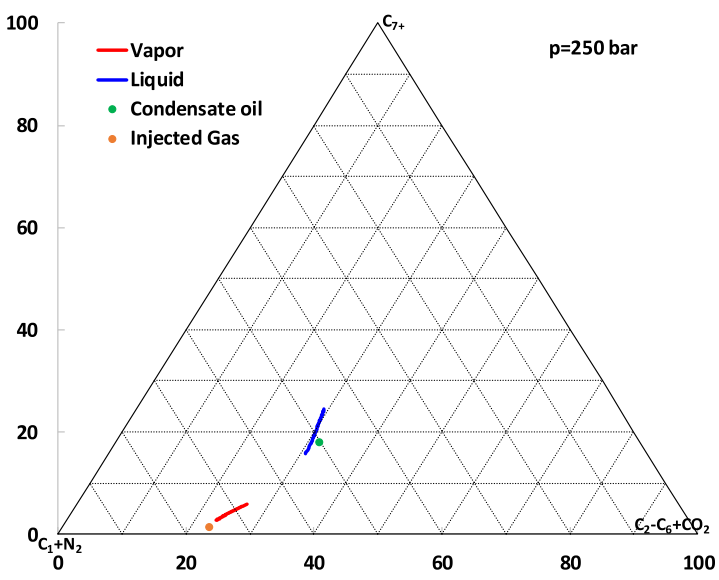

(a) Reservoir pressure 250 bar

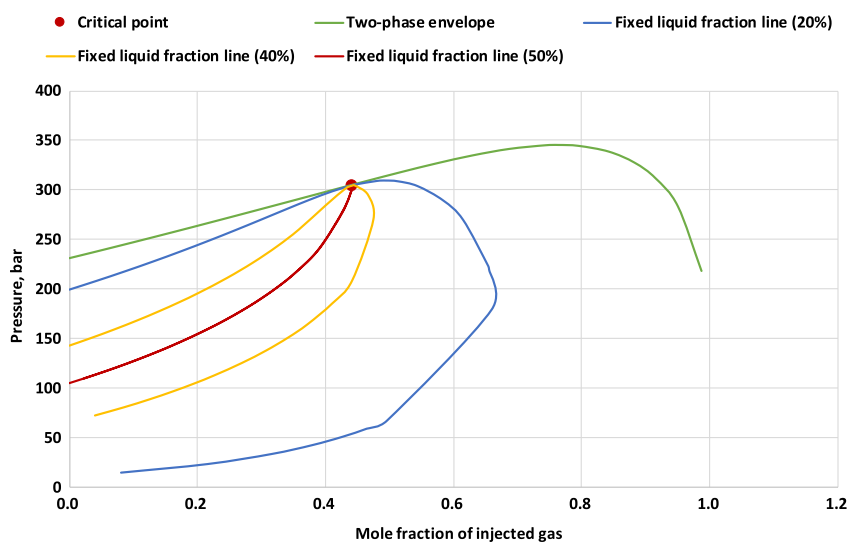

Fig. 9. Pressure-composition diagram for injecting produced gas.

\subsection{Remaining condensate gas}

In order to investigate the effect of gas injection on the remaining condensate gas, the phase behavior of remaining condensate gas mixed with different mole fraction of produced gas was performed based on the PR EOS (shown in Fig. 12). Here, the type of injection gas is set to the produced gas as shown in Table 3. It can be easily found that at the reservoir temperature of $366.5 \mathrm{~K}$, the dew point pressure of remaining condensate gas decreases with the increase of mole fraction of injection gas. For example, the dew point pressure is 231.7 bar at first, and drops to 182.6 bar when the mole fraction of injection gas is 0.8 . It means that the retrograde condensation is more difficult to occur after injecting produced gas, which is beneficial to enhance the recovery of condensate oil. Furthermore, the greater the mole fraction of injection gas, the smaller the two-phase region. This indicates that the remaining condensate gas develops toward dry gas after injecting gas.

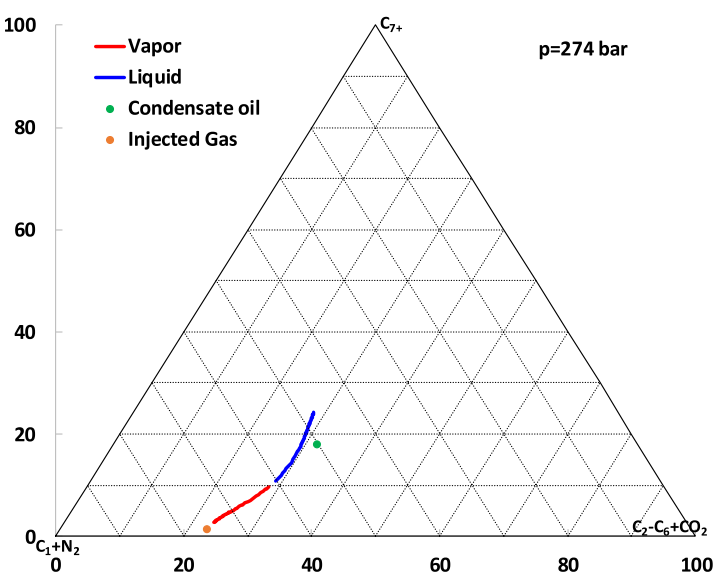

(b) Reservoir pressure 274 bar

Fig. 10. Ternary plot from multiple contact calculation for injecting produced gas at $366.5 \mathrm{~K}$. 


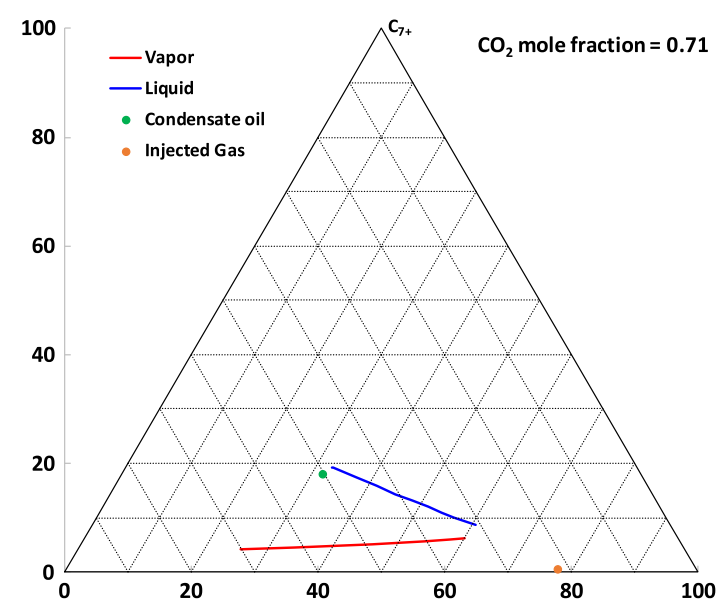

(a) $\mathrm{CO}_{2}$

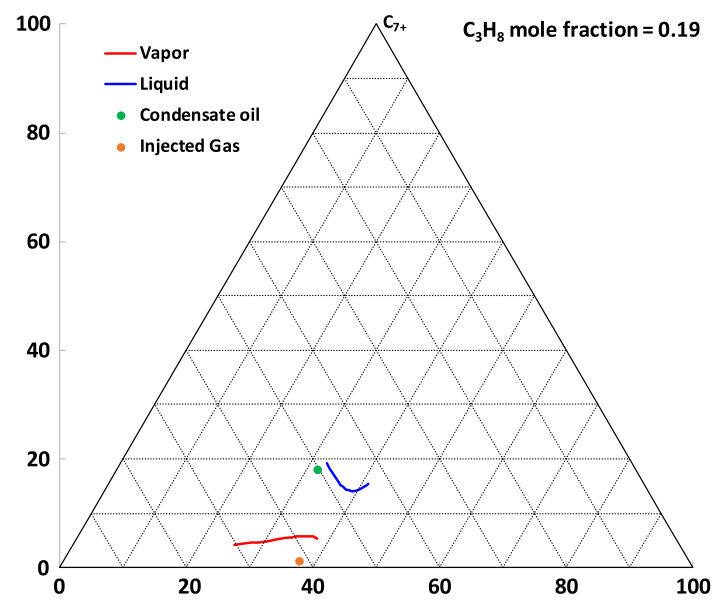

(c) $\mathrm{C}_{3} \mathrm{H}_{8}$

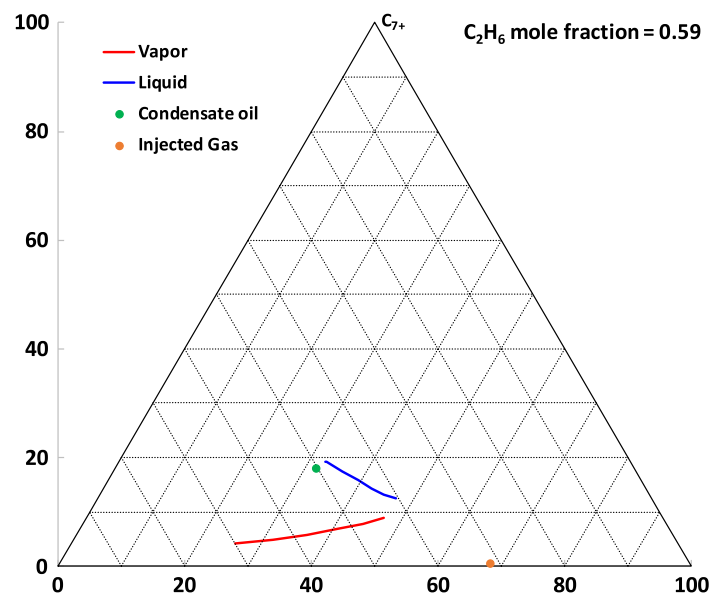

(b) $\mathrm{C}_{2} \mathrm{H}_{6}$

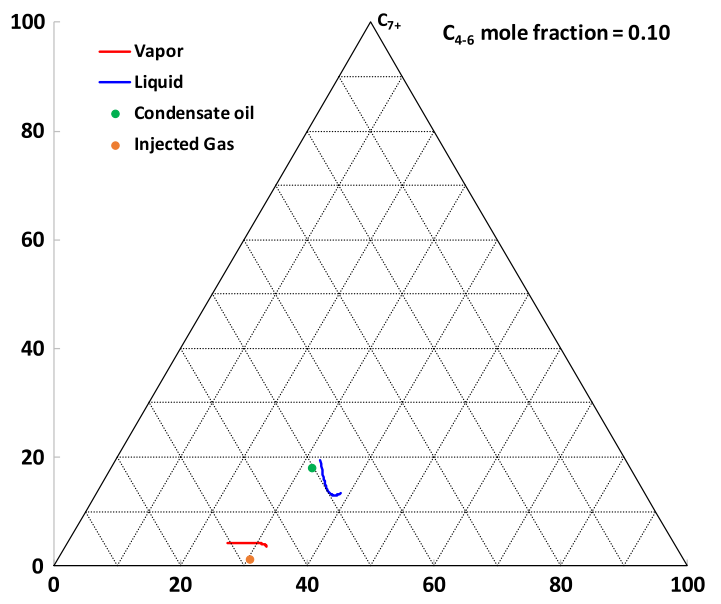

(d) $\mathrm{C}_{4-6}$

Fig. 11. Ternary plot for different enrichment agent at $366.5 \mathrm{~K}$.

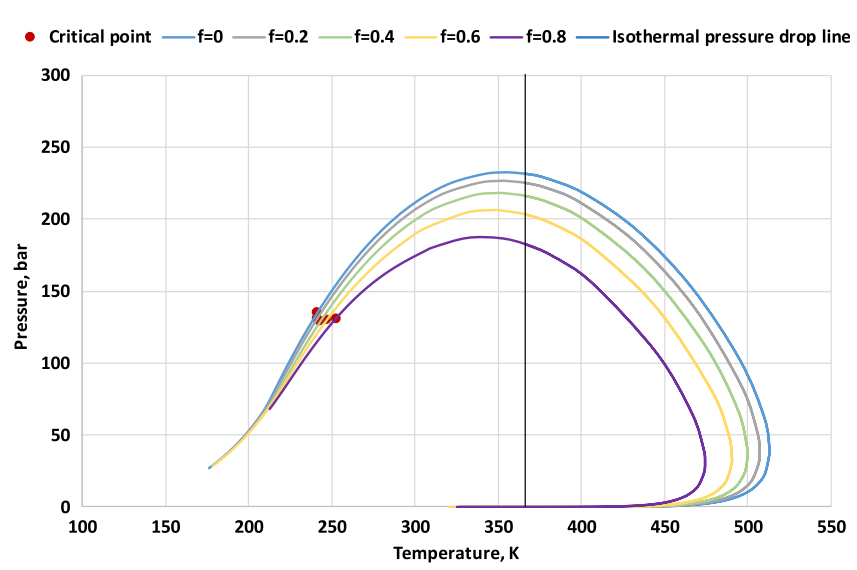

Fig. 12. Phase plot of remaining condensate gas mixed with different mole fraction of produced gas.

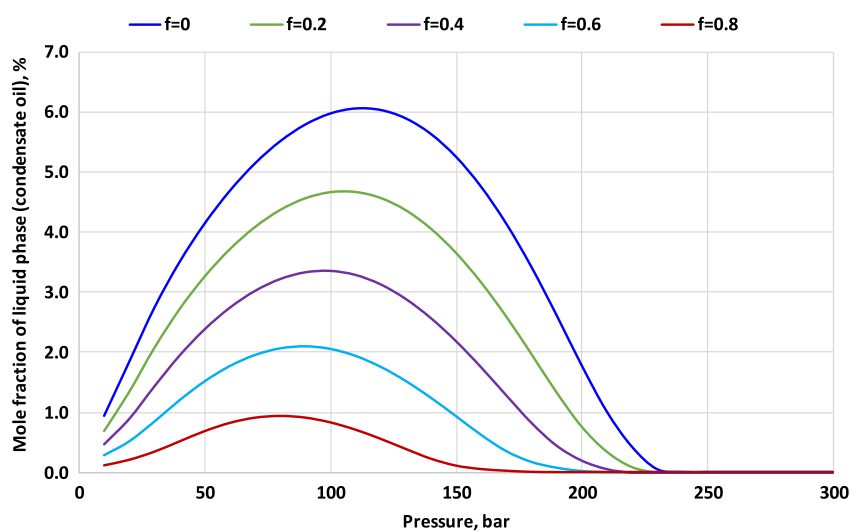

Fig. 13. The influence of injection-gas mole fraction on the condensate oil saturation precipitated from the remaining condensate gas. 
Figure 13 shows the influence of injection-gas mole fraction on the condensate oil saturation precipitated from the remaining condensate gas. As shown in Figure 13, the larger the mole fraction of injection gas, the less condensate oil is precipitated from the remaining condensate gas. For example, at the pressure of 150 bar, the condensate oil saturation is $5.3 \%$ with no gas injection, but it declines to $0.1 \%$ when the injection-gas mole fraction increases to 0.8 . This also indicates that the injection of produced gas can prevent the further precipitation of condensate oil.

\section{Conclusion}

The following conclusions can be summarized from the results of this work:

1. The phase envelopes of different pure gas in the multiple contact with condensate oil are quite different. The bell-shaped phase envelopes were generated for pure $\mathrm{CH}_{4}$ and $\mathrm{N}_{2}$, and hourglass-shaped phase envelopes for pure $\mathrm{CO}_{2}$ and $\mathrm{C}_{2} \mathrm{H}_{6}$. Different pure gas has different miscible mechanism in the displacement of condensate oil: vaporizing gas drive for $\mathrm{N}_{2}$ and $\mathrm{CH}_{4}$; condensing gas drive for $\mathrm{CO}_{2}$ and $\mathrm{C}_{2} \mathrm{H}_{6}$.

2. The greater the mole fraction of injection gas (produced gas), the more volatile the condensate oil. The main mechanism of injecting produced gas is the vaporizing gas drive. Phase-behavior reversal of petroleum mixture occurs when the condensate oil is mixed with 0.44 mole fraction of produced gas, that is, the condensate oil is converted to condensate gas.

3. The dew point pressure of remaining condensate gas decreases with the increase of mole fraction of injection gas (produced gas). The remaining condensate gas develops toward dry gas after gas injection. The injection of produced gas can prevent the further precipitation of condensate oil.

Acknowledgments. This work is supported by the National Major Projects of China (2017ZX05030).

\section{References}

Abel W., Jackson R.F., Wattenbarger R.A. (1970) Simulation of a partial pressure maintenance gas cycling project with a composition model, Carson Creek Field, Alberta, J. Pet. Technol. 22, 1, 38-46.

Ayala L.F., Ertekin T. (2005) Analysis of gas-cycling performance in gas/condensate reservoirs using neuro-simulation, Proceedings of SPE Annual Technical Conference and Exhibition, 9-12 October, Dallas, Texas, USA. SPE 95655.

Cason L.D. (1989) Waterflooding increases gas recovery, J. Pet. Technol. 41, 10, 1102-1106. doi: 10.2118/12041-pa.

Chen W.L., Liao F.M., Lv B., Miao J.J., Chang Z.Q. (2012) Retrograde vaporization dynamic phase behaviors in gas injection development of Yaha condensate gas reservoir, Nat. Gas Ind. 32, 8, 67-70.
Chueh P.L., Prausnitz J.M. (1967) Vapour-liquid equilibria at high pressures, calculation of partial molar volume in nonpolar liquid mixtures, AIChE 13, 6, 1099-1113.

Diamond L., Rondon C.R. (1990) Simulation studies of gasinjection into gas-condensate reservoirs, Proceedings of SPE Latin American Petroleum Engineering Conference, 14-19 October, Rio de Janeiro, Brazil. SPE 21060.

Fetkovich M.J. (1973) The isochronal testing of oil wellsProceeding of the Fall Meeting of the Society of Petroleum Engineers of AIME, 30 September-3 October, Las Vegas, USA. SPE 4529.

Fevang Ø, Whiston C.H. (1996) Modeling gas-condensate well deliverability, SPE Reserv. Eng. 11, 4, 221-230.

Fishlock T.P., Probert C.J. (1996) Waterflooding of gas condensate reservoirs, SPE Reserv. Eng. 11, 04, 245-251. doi: 10.2118/35370-pa.

Guo P., Du Z.M., Su C., Li H.P., Li S.L., Sun L.T. (2004) Study on recovery factor of condensate gas reservoirs with rich condensate oil exploited by depletion drive, Nat. Gas Ind. 24, 11, 94-96.

Henderson G.D., Danesh A.S., Peden J.M. (1993) Waterflooding of gas-condensate fluids in cores above and below the dewpoint, SPE Adv. Technol. Ser. 1, 2, 123-129. doi: 10.2118/22636-pa.

Jaubert J.N., Neau E., Avaullee L., Zaborowski G. (1995) Characterization of heavy oil. 3. Prediction of gas injection behavior: Swelling test, multicontact test, multiple-contact minimum miscibility pressure, and multiple-contact minimum miscibility enrichment, Ind. Eng. Chem. Res. 34, 11, 4016-4032.

Jaubert J.N., Wolff L., Neau E., Avaullee L. (1998) A very simple multiple mixing cell calculation to compute the minimum miscibility pressure whatever the displacement mechanism, Ind. Eng. Chem. Res. 37, 12, 4854-4859.

Jessen K., Orr F.M. (2003) Gas cycling and the development of miscibility in condensate reservoirs, Proceedings of SPE Annual Technical Conference and Exhibition, 5-8 October, Denver, USA. SPE 84070.

Jiao Y.W., Xie W., Di B.Z., Liang T., Liu L.W. (2012) Gas condensate phase behavior in process of cyclic gas injection, Xinjiang Pet. Geol. 33, 6, 704-707.

Li J.S., Li X.F., Zhou Y.Y., Kang X.D., Tong M. (2004) New method of cyclic gas injection for condensate reservoirs, Nat. Gas Ind. 24, 7, 76-79.

Li S., Zheng X.T., Chen G., Luo K., Liu N. (2001) Experimental investigation of retrograde vaporization of oil condensate at subsurface conditions, Acta Pet. Sin. 22, 6, 45-49.

Li Z.Y., Wang L.G., Zhang A., Huang J., Zhang K., Yao T.W., He Y.F. (2016) Effect evaluation criteria for cyclic gas injection in watered-out condensate gas reservoirs: A case study of the Dalaoba condensate gas reservoir, Tarim Basin, Nat. Gas Ind. 36, 12, 51-58.

Matthews J.D., Hawes R.I., Hawkyard I.R., Fishlock T.P. (1988) Feasibility studies of waterflooding gas-condensate reservoirs, J. Pet. Technol. 40, 8, 1049-1056. doi: 10.2118/15875-pa.

Metcalfe R.S., Fussell D.D., Shelton J.L. (1973) A multicell equilibrium separation model for the study of multiple contact miscibility in rich-gas drives, Soc. Pet. Eng. J. 13, 3, 147-155. doi: 10.2118/3995-pa.

Muskat M. (1950) Some theoretical aspect s of cycling - Part 2: Retrograde condensation about well bores, Oil Gas J. 48, 39, 53-55.

Obut S.T., Ertekin T., Geisbrecht R.A. (1986) A versatile phase equilibrium package for compositional simulation, Proceedings 
of 56th California Regional Meeting of the Society of Petroleum Engineers, 2-4 April, Oakland, CA. SPE 15083.

Pederson K.S., Fjellerup J., Thomassen P., Fredenslund A. (1986) Studies of gas injection into oil reservoirs by a cell-tocell simulation model, Proceedings of SPE Annual Technical Conference and Exhibition, 5-8 October, New Orleans, Louisiana. SPE 15599. doi: 10.2118/15599-ms.

Peng D.Y., Robinson D.B. (1976) A new two-constant equation of state, Ind. Eng. Chem. Fundam. 15, 1, 59-64.

Shtepani E. (2006) $\mathrm{CO}_{2}$ sequestration in depleted gas/condensate reservoirs, Proceedings of SPE Annual Technical Conference and Exhibition, 24-27 September, San Antonio, Texas. SPE 102284.

Standing M.B., Lindblad E.N., Parsons R.L. (1948) Calculated recoveries by cycling from a retrograde reservoir of variable permeability, Trans. AIME 17, 4, 165-190.
Taheri A., Hoier L., Torsaeter O. (2013) Miscible and immiscible gas injection for enhancing of condensate recovery in fractured gas condensate reservoirs, Proceedings of EAGE Annual Conference $\&$ Exhibition Incorporating SPE Europec, 10-13 June, London, UK. doi: 10.2118/164934-ms.

Yang S., Wei J. (2004) Reservoir physics, 1st edn., Petroleum Industry Press, Beijing.

Zhu Z.Q. (2015) Mechanism and phase behavior of retrograde condensation inhibition by secondary gas injection in the Yaha condensate gas reservoir, Nat. Gas Ind. 35, 5, $60-65$.

Zick A.A. (1986) A combined condensing/vaporizing mechanism in the displacement of oil by enriched gases, Proceedings of Annual Technical Conference and Exhibition, 5-8 October, New Orleans, LA, SPE 15493. 